\title{
ARTIFACT
}

\section{Man-Made Answers to Man-Felt Needs}

by Per Mollerup, Mollerup Designlab A/S, Fredriksberg

Artifacts are man-made answers to man-felt needs. Researchers and authors have described the answers, needs, values, processes, and economies involved. This article synthesizes and expands on some of their findings.

Do artifacts answer needs? Not always. Sometimes, the process leading to an artifact rather than the resulting artifact is the answer to a felt need. This is the case when artists create because they must create. The product becomes a by-product. Sometimes, industrial products are questions rather than answers. They ask, "Won't you buy me?" rather than announcing, "This is what you asked for!"

This article does not distinguish between artifacts resulting from supply push and those resulting from demand pull. Rather, it acknowledges that there are good answers and not-so-good answers to the needs of intended users.

\section{MASLOW REDUX}

By definition, designed artifacts do not just happen. They are the result of processes inspired by the wish to change an existing situation into a preferred situation. Less preferred 'existing situations' are characterized by unfulfilled needs.

Abraham Maslow's well-known hierarchy of human needs (Figure 1) offers a relevant starting point for discussing the needs met by artifacts. Maslow divided human needs into four deficiency needs and four growth needs. Deficiency needs deal with physiological needs, safety needs, belongingness, love needs, and esteem needs. According to Maslow, each lower deficiency need must be met before moving to the next level.
According to Maslow, growth needs become important as deficiency needs are met. Growth needs include needs to know and understand, aesthetic needs, self-actualization, and transcendence. Some researchers question the exact order of these needs. Everybody seems to accept that attention to serious business precedes attention to fun. At the same time, many of us understand that many needs exert their influence concurrently.

Some suggest that Maslow's hierarchy can be used to describe the kinds of information that individuals seek at different levels. I agree. What is more, Maslow's hierarchy can be used to understand the material artifacts that respond to different needs and Maslow's hierarchy can describe the history of human production and design.

In primitive societies of hunters and gatherers, we find survival design. Survival design involves tools for catching and killing as well as tools for keeping
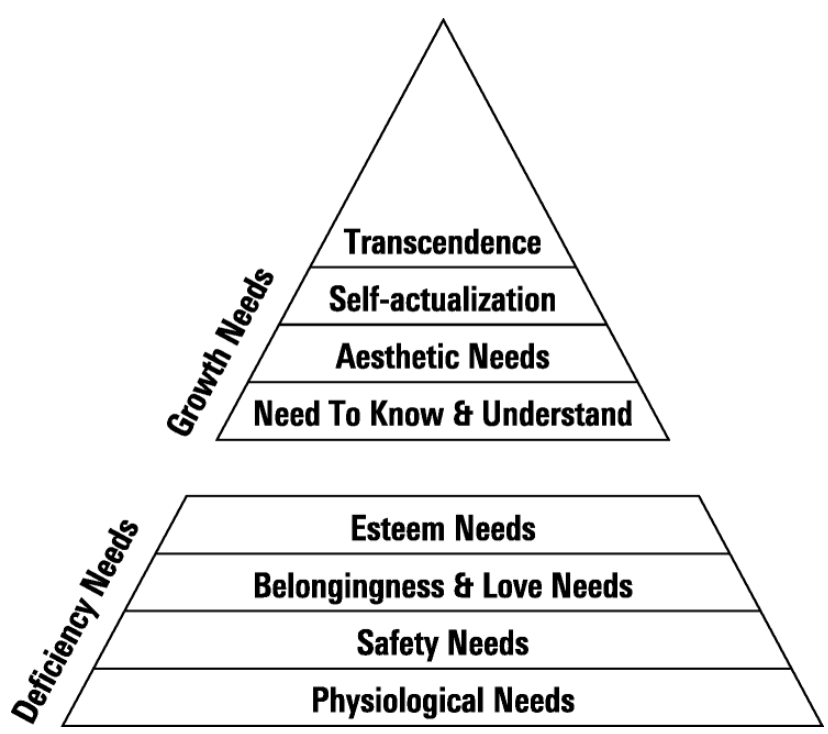


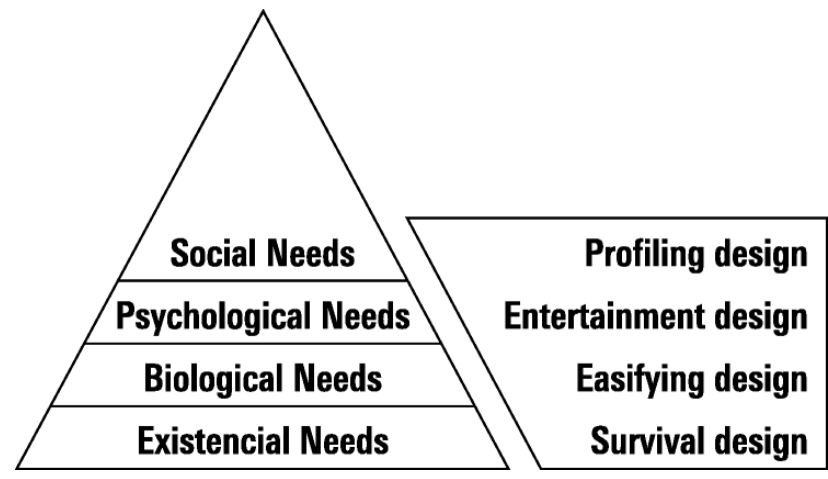

Figure 2.

warm and dry. Existence requires survival design. The connection to the lowest level of Maslow's hierarchy is obvious.

As primitive societies become less primitive, they find time to develop tools that make life easier. We call the process and the result easifying design. Easifying is a neologism. We must name a thing to know it. Tools and machines for household, farming, and manufacturing belong to the category of easifying design. Even though less primitive societies begin to work with easifying design they do not forego survival design. Survival design remains important, even as other tools come into play.

Maslow's hierarchy contains no need for making things easier. However, easifying design means bodily comfort in the form of less muscular work. Seen on a larger canvas, easifying design facilitates increased efficiency, yielding more output with less input. More output means the ability to meet more of Maslow's needs.

As societies evolve further, they make tools for pleasure, entertainment design. Some tools serve both easifying and pleasure, but they are typically legitimized by the ease factor. Automobiles are a case in point. We buy a car because we need it. We buy a car that costs twice as much as necessary for hedonic reasons. We use other tools exclusively for pleasure. This includes sports equipment and electronic entertainment gear. Entertainment design relates to Maslow's aesthetic needs.

At this stage of development, societies can meet lower needs in more refined ways than required by strict functionality. Food can be tasty, beverages can be intoxicating, cars can be fun to drive, clothes can be interesting to see, to wear, and to be seen with, and homes can be decorated with - greater or lesser - taste. (The concept of taste as a metaphor for all kinds of aesthetic discrimination was only invented in the eighteenth century. Before that time, taste exclusively meant a sensation in the taste buds.)

After further development, societies demand and design products that help us to express ourselves. Profiling design relates to the upper levels of Maslow's hierarchy. Profiling products are the artifacts that we acquire to announce ourselves to our surroundings, telling others what kind of people we are. Rolexes, Guccis, and Porsches belong here. So do much cheaper and sometimes anonymous products including T-shirts, blue jeans, and the sneakers that help us to define our role in society. We are what we buy.

Profiling design can be classified in four categories: body, inner shell, outer shell, and peripherals. The body includes all kinds of alterations and improvements from lip-gloss and breast lifts to surgical transmogrification. The inner shell comprises all kinds of dresses, while the outer shell includes houses and shelters. Peripherals include cars, boats, and other expressive tools.

Artifacts can belong to more than one of the four major design categories. A Humvee, the fourwheel-drive monster car originally introduced in the Gulf War, was created for survival and easifying. Later, when the Humvee also became popular for non-military purposes, it transcended the original categories to become a source of aesthetic pleasure, and a way to inform passers-by what kind of person they have just seen. Buy one, get four: survival, easifying, pleasure, and profiling design.

As societies develop and climb the Maslow hierarchy, they move from satisfying existential needs to satisfying biological, psychological, and social needs. The corresponding four types of design do not address all Maslow's needs, since not all of these require explicitly material answers. A modified "Maslow hierarchy" focused on material needs would comprise existential, biological, psychological, and social needs (Figure 2). 


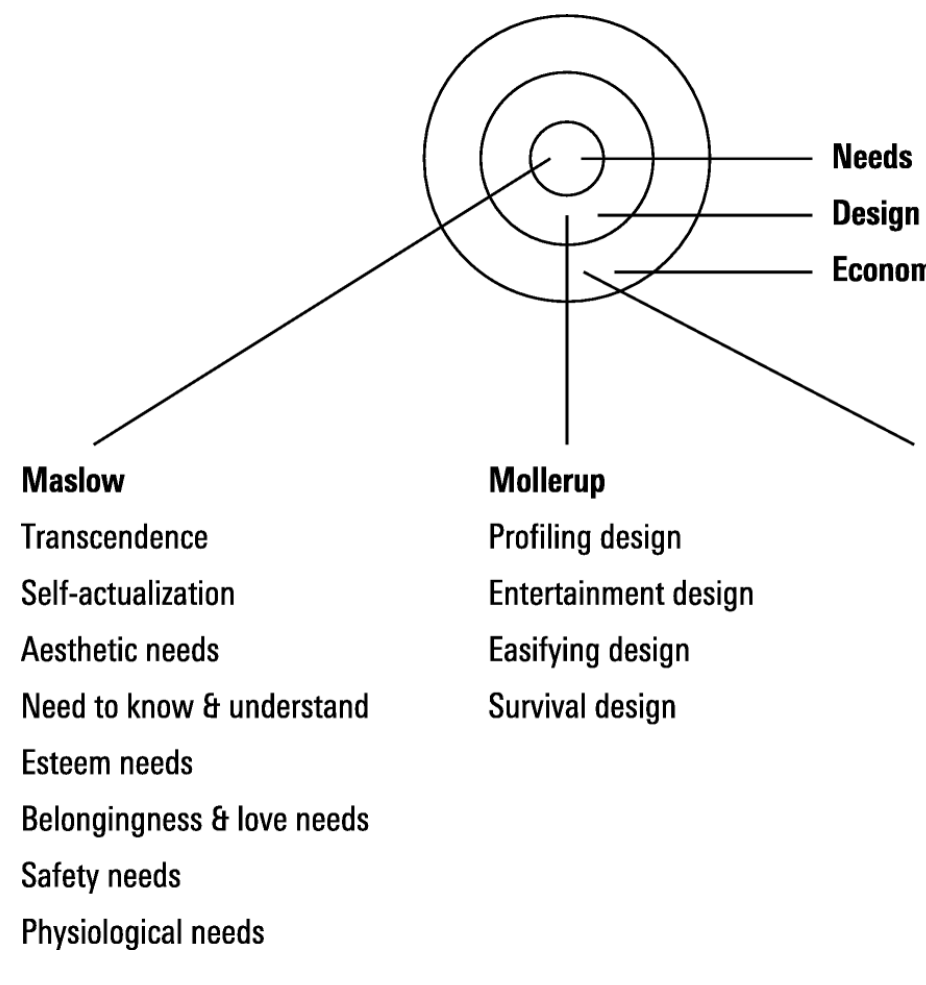

\section{ECONOMIC FRAMEWORKS}

The extent to which human needs are met is to a high degree the function of a society's economic development. The economic development described by Daniel Bell in The Coming of the Post-Industrial Society reflects the move from the bottom to the top of Maslow's hierarchy and the move from existential to easifying design.

Before there was any economic development - an organized system of production, distribution, and consumption - hunters and gatherers met the material needs of their people. Daniel Bell describes economic development by discerning between primary, secondary, and tertiary economies.

In a primary economy, the main source of income involves taking nature's products more or less unchanged from source to market. The products of a primary economy are animal, vegetable, or mineral commodities. They are raised and slaughtered, dug and mined, or grown and harvested with little or no processing. Commodities are standard. Buyers do not care whether commodities come from one supplier or another. Most of the time they cannot know.

Commodities are sold anonymously at markets. Fish from the sea, wood from the forests, metal from the earth, and meat from the cattle are typical commodities in a primary economy. The agrarian
Figure 3.

Needs, design, economies.

\section{Bell, Pine \& Gilmore}

Transformation economy

Experience economy

Tertiary/service economy

Secondary/industrial economy

Primary/agrarian economy

Hunters \& gatherers economy that followed the hunting and gathering society is the archetypical primary economy. Most people work with and earn a living from agriculture.

As time goes by, agrarian or primary economies develop into industrial or secondary economies. In a secondary economy, most people work in industry, where they create value by producing goods. Goods are more advanced offerings than commodities. Since the industrial revolution, much of the labour force has shifted from agriculture to industry for two reasons. Agriculture has been mechanized by easifying design, and needs less labour. While industry has required many workers to run the machines, increasingly advanced machinery replaces an increasing number of workers who move on into the service sector.

This takes us to the tertiary economy, also known as service economy. Most employers and most sources of income - two sides of the same coin are now found in the service sector. Actions in the form of service are the product rather than tangibles such as commodities and goods. Actors in the service sector do work that we should otherwise do ourselves or do without. Immaterial services are no less easifying than material easifying design.

Primary, secondary, and tertiary economies are not mutually exclusive. In most developed countries, they coexist in varying proportions. However, most 
of the countries in the world are still characterized by primary economies. In these countries, most people are employed and most value is created in agriculture and in mining, and oil and gas extraction. This is not the case in the developed countries. In Denmark, only $5 \%$ of the labour force works in agriculture, a sector using two-thirds of Denmark's land to make enough food for a population three times larger than Denmark's five million people.

Evolving economies move from agriculture to industry to services. They move from preindustrial to industrial and post-industrial economies, from commodities to goods and services. But the world does not stop there. Two American economists, Joseph Pine and James Gilmore, have identified and described a fourth economy, the Experience Economy, in a book of the same title. Some say that experiences are already covered by the tertiary economy. However, Pine and Gilmore tell us that the difference between experiences and services is as great as the difference between services and goods.

However, according to Pine and Gillmore, the experience economy is not the final stage in economic development. The ultimate offerings are not experiences but transformations, processes in which people double as input and output. Customers, clients, guests, and patients come as they are and leave as new persons. All types of spiritual coaching, education, beautification and medical repair, and adjustment fall into the category of transformation offerings. What is more important than ourselves? Does our present persona represent us in the way we wish?

These evolving economies describe the ways we organize production to satisfy our needs, partly by producing material artifacts, partly by immaterial services. No wonder the stages of economic development strongly resemble Maslow's hierarchy and the four types of material design (Figure 3).

Maslow's hierarchy, the categories of material design, and the different stages of economic development describe three important aspects of material artifacts. They explain why we make them, they describe what they are, and they demonstrate how our society adjusts to their production.

\section{REFERENCES}

Bell, Daniel (1973). The Coming of Post-Industrial Society. New York: Basic Books.

Pine, Joseph B., \& Gilmore, James H. (1999). The Experience Economy. Boston, MA: Harvard Business School Press.

\section{CORRESPONDENCE}

Professor Per Mollerup, Dr.Tech.

Swinburne University of Technology

Faculty of Design

E-mail: pmollerup@swin.edu.au

Published online 2006-04-21

ISSN 1749-3463 print/ ISSN 1749-3471

DOI: 10.1080/17493460600655165 